\title{
THE BACKWARD ELIMINATION OF ERRORS IN MENTAL MAZE LEARNING ${ }^{1}$
}

\author{
BY JOSEPH PETERSON
}

George Peabody College for Teachers

In another paper the writer has shown that an animal through sheer probability will, with a continued series of efforts, reach the food box in a maze; and further, that on the basis of frequency of exercise (if we grant the operation in learning of certain other factors appearing to be indispensable to learning) the errors of entrance to blind alleys should be gradually eliminated in what has been called the backward order, that is, the errors near the food box should first disappear, and the others should be eliminated in order, speaking generally, from this point back toward the entrance place in the maze. In the earlier paper errors were interpreted as entrances to blind alleys; return runs not bringing about such entrances were not counted in the error score. It was shown that the first blind alley is passed, on the basis of probability solely, $3 / 4$ of the times that it is encountered in forward runs by an animal, and that the animal is turned back by it toward the entrance $1 / 4$ of the times. The next blind is likewise passed $3 / 4$ of the times that it is encountered, or $3 / 4$ of $3 / 4$ of the number of times that the first blind is reached. Speaking generally, in $n$ trials the $m$ th blind from the entrance would be passed in forward runs $(3 / 4)^{m}$ of the number of times that the first blind is reached. The tenth blind, for example, would be passed $(3 / 4)^{10}$ - or a little more than $1 / 18$ - of the number of times that the first is encountered.

This matter is, of course, vastly complicated by partreturn runs. Disregarding these part-returns for the sake of simplicity, and assuming that each return run will take the

${ }^{1}$ Read in part in Section H of the A. A. A. S., St. Louis, Dec. 30, 1919. 
animal back to the starting place in the maze, i.e., to the entrance, we find that when any blind alley is passed $n$ times the one next before it will, on the basis of pure chance, be passed $4 n / 3$ times. "In general, in a maze with $y$ blind alleys the number of times that the first would be passed in forward runs in $n$ trials is $(4 / 3)^{y-1}$ times the number that the last would be passed, i.e., (4/3) $)^{y-1} n .^{\prime \prime}$ The last blind would be passed $n$ times, as each trial ends only when this blind alley is passed. In a maze of ten blind alleys, therefore, the last blind would be passed $n$ times in $n$ trials, the next before it 1.33n times, and the eighth, seventh, sixth, fifth, fourth, third, second, and first, would be passed $1.78 n, 2.37 n, 3.16 n$, $4.22 n, 5.62 n, 7.50 n$, 10.00n, and $13.33 n$, respectively.

On this basis it was found, on the above assumption of complete returns, that the ratio of entrances into the respective blind alleys to passing them successfully, whether entered or not, would be as follows:

$$
\begin{aligned}
& 13.33 n-.25: 13.33 n \text {, for the first blind alley, } \\
& 10.00 n-.25: 10.00 n \text {, for the second, } \\
& 7.50 n-.25: 7.50 n \text {, for the third, } \\
& 5.62 n-.25: 5.62 n \text {, for the fourth, } \\
& 4.22 n-.25: 4.22 n \text {, for the fifth, } \\
& 3.16 n-.25: 3.16 n \text {, for the sirth, } \\
& 2.37 n-.25: 2.37 n \text {, for the seventh, } \\
& 1.78 n-.25: 1.78 n \text {, for the eighth, } \\
& 1.33 n-.25: 1.33 n, \text { for the ninth, and } \\
& n-.25: \quad n, \text { for the tenth. }
\end{aligned}
$$

It will be noticed that this ratio of entrances to passes constantly decreases toward the last cul de sac, thus favoring 'exercise in running past' to 'exercise in running into' the blind alleys, the advantage being increasingly greater with nearness of the blind alley to the food box. It is important to note also that this advantage of exercise in running past blinds over exercise in running into them also increases as $n$ approaches a small number, as I, 2, or 3, its value during the early trials when greatest progress is made.

1 Peterson, Jos., 'Frequency and Recency Factors in Maze Learning by White Rats,' Jour. Animal Behov., 1917, 7, 344. 
This quantitative explanation is sufficient to account for the backward elimination of errors in the maze, probably, even if we assume only a general motivating effect of the food, operating equally at all parts of the maze, an assumption, however, not intended here. There is apparently no need of assuming any so-called retroactive association, the existence of which in any case of learning may well be regarded as not established.

In the other paper a question was raised regarding the results of an experiment by Hubbert and Lashley, ${ }^{1}$ showing that errors made by entrances into blind alleys numbered with even numbers in Fig. I, errors of their type I., were eliminated in less than two thirds as many trials as were errors of entrances into blinds numbered in odd numbers. It will be noticed that the errors of type I. are made by the animal's running past the place where it should turn, while the other type of error, type II., is caused by a turn in the wrong direction. The serial backward elimination of errors of type II. was found in the main to agree with the results of Miss Vincent, Carr, the present writer, and others; while no such serial elimination of type II. resulted. This apparent contradiction to the general rule of backward elimination was explained tentatively in our earlier paper as due to the fact that when an animal is just correcting in the last stages the errors of running into blind alleys, it frequently is thrown into confusions (probably by changes in the general kinæsthesis) that result in entrances into later blinds which it has already learned to avoid under normal conditions. Since the animal learns at an early stage in the game, comparatively, to keep the forward direction on emergence from blinds ${ }^{2}$ and also to orient itself in general toward the center of the circular maze, as was found by Hubbert and Lashley, it would be expected that a combination of these factors or tendencies would throw it into errors of type I. in parts of the maze nearer the food box than are the sources of the dis-

1 'Retroactive Association and the Elimination of Errors in the Maze,' Ibid., $1917,7,130-138$.

2 Peterson, Jos., 'Behavior Monog.,' Ser. No. 15, 1917, $24 \mathrm{ff}$. 
turbances. It is our purpose here to present results of an experiment on human subjects with what we have chosen to call a mental maze, a method which ehminates all such confusing spatial factors as those just mentioned.

\section{The Experiment}

The present form of procedure was arrived at after considerable experimentation. First, choices of right or left were presented to the subject at the successive stages through

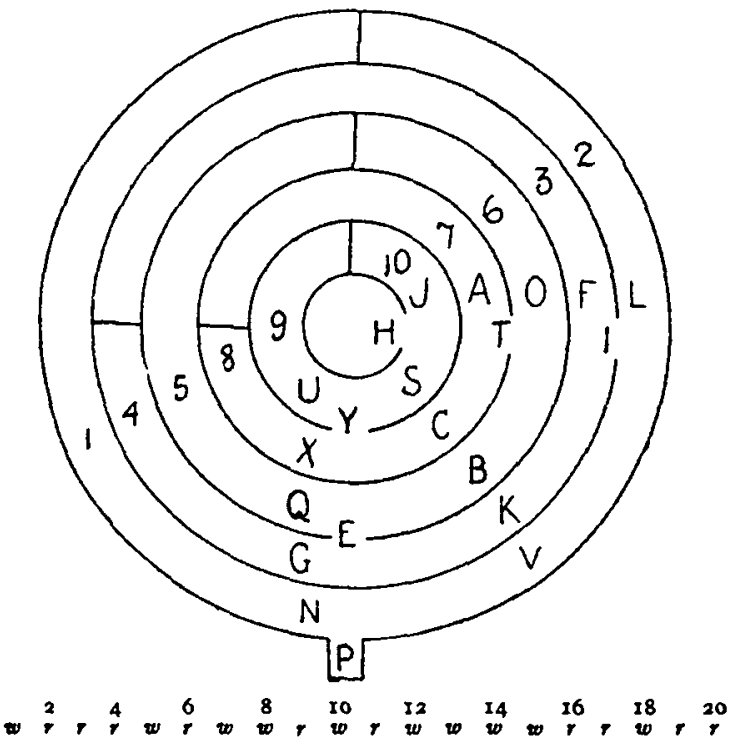

Frg. I. The Mental Maze and Chance Order Schedule.

the maze; it was then found that the different parts of the maze should have a constant designation, so each part was lettered in a meaningless order as shown in Fig. I. It was desirable to present each pair of letters at any bifurcation simultaneously, but this required an elatoration of apparatus that seemed unadvisable for the practical and wide use of the experiment, though it is still on the program for further experimentation. Tentative experimentation showed that a simpler form of procedure giving reliable results is possible, provided that a pure chance order of presentation of the two 
alternatives be followed, and that the same emphasis and tone of voice be used throughout. It was therefore decided to follow a chance order schedule or program, exactly the same for all subjects. Accordingly a program was prepared and written just below the drawing of the maze, as shown in the figure. The letter $r$ means to call out first the right letter of the two alternatives, and $w$ means to call out first the wrong letter. The numbers occurring just above these letters were found to save much time in determining at the beginning of each new trial just where to start, as will be made clear later.

The experimenter, $E$, sits behind a screen with his finger on the schedule of $r$ 's and $w$ 's. $S$ is given the following instructions to read:

Do you know what a maze is? It is a winding way to some goal, but it has many blind alleys which will lead to error if you enter them. I have drawn a maze which I will show you when I am through with all the subjects that I shall use in this experiment. Wherever there is a choice of two alleys, each alley is designated by a letter. No two parts are lettered the same, and the letters have a constant position in the maze. Beginning at the entrance of the maze, I call out two letters at a time, and you are to choose one of them; then I call out two more; and so on. Whether the right or the wrong letter is called out first is a matter that is determined wholly by flipping a coin, that is, by chance; so you needn't attend to the order. The position of any letter in the maze, moreover, has no relation to its position in the alphabet; letters occur in random order. The problem is to see with how few errors you cen get to the goal, and how soon you can learn to follow the true path with no errors at all. You are through when you get to the goal three times in succession without error. You will be told each time when the goal is reached and the number of errors you made in reaching it, but must find out for yourself where the errors are. Remember, accent and order of calling out letters have no significance. Don't attend to them.

After recording $S$ 's name and the time of beginning the experiment, $E$, following the program, calls out $\mathrm{N}-\mathrm{V}$. If the subject chooses $\mathrm{N}$, the next letters called out are $\mathrm{V}-\mathrm{P}$; but if the subject chooses $\mathrm{V}$ the first time, I-L are called out; and so on. The letters that the experimenter calls out at any time depend wholly on where $S$ has taken him in the maze, but the order of the letters, that is whether the right or the wrong alternative is presented first, is determined by the schedule, which is gone through from beginning to end and repeated in that order till the goal is reached. On $S$ 's second trial $\mathrm{V}$ is called before $\mathrm{N}$; that is, the experimenter starts with the second letter in the schedule. Each successive 
trial begins with the letter of its number in the chance schedule, the twenty-first trial beginning again at the first letter, and therefore following the same order as the first trial.

The writer conducted all the experiments personally, and he practiced giving the letters in a monotonous tone, always accenting a little the last letter of the pair, whether or not one of the pair had been included in the preceding pair of alternatives, as is the case whenever an error has been made by the subject. When the subject gets to the goal he is told: "That is the goal;" not, " $\mathrm{H}$ is the goal;" for that would unduly emphasize $H$ in his mind. The subject is then told that another trial begins, so that he will know exactly what he is expected to do. He knows nothing of the chance program, or the place in it of the start on any new trial, other than he could infer from the instructions.

In the practical operation of the experiment other precautions were developed. It was found that in spite of the explicit instructions regarding a chance-order procedure, some subjects tried to choose the first letter called out, on failure otherwise, or the second, or the first one three times and then the second one three times, etc. Some even "tried to spell words," so it became necessary to throw out the records of all such students, four in number, as they made no progress at all toward a solution without error. To make sure that $S$ was not either consciously or unconsciously following any order, the writer decided to put a dot under every choice of the first letter called out. With practice this was found to be easily done, and to leave a record for study that is accurate in all essential details. To guard against errors in following the schedule, $E$ moved his finger forward to the next letter each time while recording $S$ 's response; that is, it was found best to reduce the whole process of calling out letters and recording responses to a fixed routine.

The experiment from the first proved very interesting, giving $E$ an opportunity to study in actual operation and in ever varying detail, association processes that we have been prone too much to consider only in tables of averages, and in curves of results. Several subjects require at least two hours 
to complete the test, while a few good ones do it in a surprisingly short time. The best record to date is twelve minutes for the learning, with a total of only seventeen errors. The experiment seems to have important diagnostic values which we cannot consider in the present paper. The student, for instance, who made the remarkable record just quoted is a young Chinese woman of excellent mental ability and unusual initiative and objectivity of mind, as this attitude has been described elsewhere. ${ }^{1}$ Students of poor initiative seem to fall into profitless routine that takes them nowhere.

It will add to clearness to give here the record of one subject in a single trial, that is, till the goal is reached. We shall take the first trial of a young woman who completed the experiment in forty-five trials.

Trial 1. $N^{*} V \mathrm{~L}^{*} \mathrm{~V}^{*}(\mathrm{P}) \mathrm{N}^{*} \mathrm{~V} \mathrm{~L}^{*} \mathrm{~V}^{*}(N) \mathrm{P}^{*} N^{*} \mathrm{~V}$ $L^{*} \mathrm{I} \quad \mathrm{F}^{*} \mathrm{I}^{*}(\mathrm{~V})(P) \mathrm{N}^{*} P^{*} \quad V \quad I \quad K G^{*} E Q^{*} E^{*}(K)$ (F) $K \mathrm{E} Q^{*}$ B $\mathrm{T} A^{*} C Y \mathrm{Y} S H$ (goal). I 8 errors.

In the above illustration a letter in italics indicates that the first of the alternatives called out to $S$ was chosen; an asterisk after a letter indicates an error (i.e., either an entrance into a blind alley on a forward run, or a return toward the entrance on emergence from a blind); and a letter in parenthesis stands for an uncritical choice, made while going toward the entrance of the maze and at a juncture where no error is possible, as we have defined errors. For each of these meanings the writer has a simple mark that he makes while the experiment is in progress. A complete objective record of all the subject's significant responses is thus easily made possible.

\section{Subjects}

The subjects whose records we present in this paper were five men and fourteen women. The women and three of the men were students in the writer's section of general psychology. One of the men is an instructor in psychology, and one is a graduate student. Five of the students reacted to a different lettering of the maze from that shown in Fig. I,

${ }^{1}$ Ruger, H. A., 'The Psychology of Efficiency,' Archio. of Psychol., No. 15, 1910.

Peterson, Jos., 'Experiments in Rational Learning,' Psychol. Reo., 1918, 25, 463. 
the purpose of the change being to make sure that results were not conditioned in an important manner by any particular lettering or letter associations.

\section{RESULTS}

Table I. summarizes the results of the nineteen subjects in such a form as to show where and in what trials the 2,956 errors occurred. The totals of the columns, at the base of the table, are arranged to show separately $(x)$ the errors of returning toward the entrance of the maze on emergence from blind alleys, (2) the errors of entrance into blind alleys of odd numbers, Hubbert and Lashley's type II. errors, made by turns in the wrong direction, and (3) the errors of entrance into blinds of even numbers, type I., made by wrongly passing a door.

It will be noticed that our experiment, which eliminates the various disturbing and irrelevant spatial factors peculiar to different mazes, gives results that show practically an equality of errors of type I. and type II., as these errors have already been defined. Moreover, the median of the trials by our several nineteen subjects in which the last error at each part of the maze occurred, shows the same fact of equality in difficulty of these two types of errors, as would, of course, be expected on the basis of probability. This median in each case is found as follows: The last entrance to each blind alley by every subject is tabulated and the trial on which it was made is recorded. We thus have nineteen last entrances for each cul de sac. The median of each set of these nineteen numbers is found, and the average of the medians of errors of type $I$. is obtained and compared with the average corresponding to it for type II. errors. The average of these medians is 6.6 in each case. The results from which these averages were derived will be found in Table II. The median in this case is chosen because it is not affected by certain accidental conditions of extreme cases as is the average.

Studies of the individual records, a matter that we cannot consider here, show that not infrequently when errors of 
TABLE I

Showing the Dibtribution of the 2,956 Errors of Nineteen Subjects in the Mental Maze Learning

\begin{tabular}{|c|c|c|c|c|c|c|c|c|c|c|c|c|c|c|c|c|c|c|c|c|c|c|c|}
\hline \multirow[b]{2}{*}{ Trials } & \multicolumn{23}{|c|}{ Parts of the Maze * } \\
\hline & $\mathbf{P}$ & $\stackrel{x}{N}$ & $\mathbf{V}$ & $i^{2}$ & I & F & $\mathbf{K}$ & G & $\mathbf{E}$ & $\mathbf{S}$ & $\mathbf{B}$ & $\stackrel{6}{0}$ & $\mathbf{T}$ & A & C & $\stackrel{8}{x}$ & $\mathbf{Y}$ & 8 & $\mathbf{S}$ & $\stackrel{x}{\mathrm{~J}}$ & $\mathbf{H}$ & $\begin{array}{c}\text { Totel } \\
\text { Estors }\end{array}$ & $\begin{array}{l}\text { Av. Errors } \\
\text { per S }\end{array}$ \\
\hline 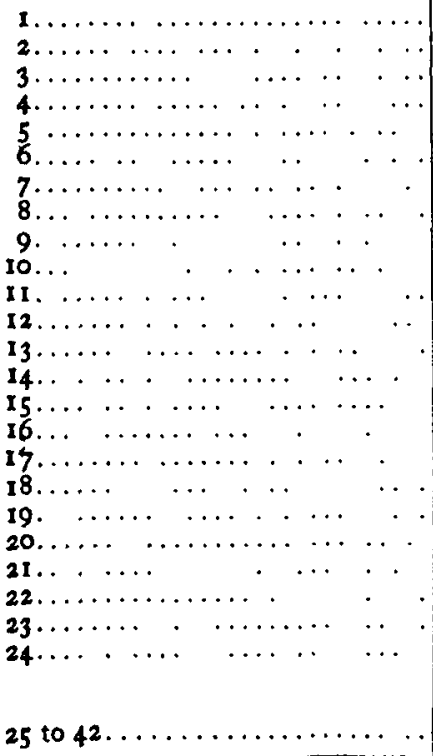 & $\begin{array}{r}59 \\
20 \\
21 \\
26 \\
23 \\
21 \\
7 \\
6 \\
9 \\
9 \\
7 \\
2 \\
1 \\
2 \\
3 \\
2 \\
3 \\
1 \\
1 \\
1 \\
2\end{array}$ & \begin{tabular}{|r|}
67 \\
23 \\
26 \\
29 \\
28 \\
24 \\
14 \\
11 \\
10 \\
12 \\
12 \\
9 \\
5 \\
6 \\
6 \\
5 \\
4 \\
4 \\
3 \\
3 \\
5 \\
3 \\
2 \\
1 \\
om he \\
pa \\
19 \\
pa
\end{tabular} & $\begin{array}{r}63 \\
49 \\
14 \\
17 \\
15 \\
17 \\
3 \\
3 \\
5 \\
6 \\
3 \\
4 \\
1\end{array}$ & \begin{tabular}{|r|}
74 \\
56 \\
13 \\
26 \\
21 \\
19 \\
14 \\
7 \\
11 \\
9 \\
11 \\
11 \\
7 \\
1 \\
3 \\
2 \\
4 \\
1 \\
1 \\
1 \\
1 \\
3 \\
1 \\
2 \\
only \\
of th \\
4
\end{tabular} & $\begin{array}{r}20 \\
12 \\
12 \\
13 \\
11 \\
12 \\
7 \\
4 \\
3 \\
6 \\
2 \\
1\end{array}$ & \begin{tabular}{r|}
21 \\
15 \\
21 \\
22 \\
18 \\
13 \\
12 \\
9 \\
6 \\
9 \\
6 \\
2
\end{tabular} & $\begin{array}{r}45 \\
24 \\
16 \\
14 \\
10 \\
12 \\
1 \\
4 \\
1 \\
3 \\
2 \\
1\end{array}$ & $\begin{array}{r}52 \\
38 \\
22 \\
19 \\
18 \\
19 \\
6 \\
10 \\
8 \\
8 \\
9 \\
5 \\
5 \\
3 \\
6 \\
3 \\
6 \\
4 \\
3 \\
3 \\
2 \\
2 \\
1 \\
1\end{array}$ & $\begin{array}{r}18 \\
13 \\
6 \\
6 \\
15 \\
6 \\
2 \\
6 \\
2 \\
5 \\
4 \\
2\end{array}$ & $\begin{array}{r}15 \\
18 \\
15 \\
14 \\
18 \\
6 \\
8 \\
11 \\
4 \\
4 \\
4 \\
4 \\
4 \\
3 \\
6 \\
2 \\
5 \\
2 \\
2 \\
1 \\
3 \\
1\end{array}$ & $\begin{array}{r}13 \\
10 \\
6 \\
7 \\
7 \\
4 \\
17 \\
2 \\
3 \\
3 \\
2 \\
1\end{array}$ & $\begin{array}{r}21 \\
20 \\
17 \\
14 \\
17 \\
10 \\
23 \\
7 \\
11 \\
10 \\
12 \\
8 \\
6 \\
5 \\
5 \\
4 \\
6 \\
4 \\
2 \\
1 \\
1 \\
1 \\
1 \\
1\end{array}$ & $\begin{array}{r}11 \\
11 \\
13 \\
3 \\
10 \\
3 \\
2 \\
3 \\
2 \\
2 \\
1\end{array}$ & \begin{tabular}{r|}
18 \\
18 \\
13 \\
6 \\
15 \\
7 \\
7 \\
7 \\
5 \\
8 \\
10 \\
9 \\
7 \\
6 \\
5 \\
4 \\
3 \\
3 \\
2 \\
1 \\
1 \\
1 \\
1 \\
ten m
\end{tabular} & $\begin{array}{r}6 \\
11 \\
6 \\
7 \\
6 \\
2 \\
8 \\
2\end{array}$ & \begin{tabular}{r|}
10 \\
17 \\
10 \\
11 \\
12 \\
6 \\
13 \\
4 \\
4 \\
5 \\
9 \\
5 \\
3 \\
4 \\
4 \\
4 \\
3 \\
5 \\
2 \\
2 \\
1
\end{tabular} & $\begin{array}{r}5 \\
4 \\
13 \\
2 \\
3 \\
4 \\
3 \\
2 \\
3 \\
2 \\
1 \\
2 \\
2\end{array}$ & \begin{tabular}{r|}
8 \\
10 \\
17 \\
8 \\
9 \\
8 \\
7 \\
5 \\
7 \\
2 \\
8 \\
5 \\
4 \\
3 \\
2 \\
2 \\
5 \\
2 \\
2 \\
1 \\
1 \\
1 \\
1 \\
1 \\
ith e \\
16 \\
1
\end{tabular} & erro & $\begin{array}{l}9 \\
3 \\
5 \\
3 \\
3 \\
4 \\
3 \\
2 \\
4 \\
1 \\
1 \\
1\end{array}$ & & $\begin{array}{r}540 \\
372 \\
267 \\
247 \\
260 \\
197 \\
155 \\
103 \\
102 \\
101 \\
112 \\
71 \\
44 \\
37 \\
53 \\
42 \\
54 \\
33 \\
20 \\
17 \\
19 \\
15 \\
8 \\
9 \\
\end{array}$ & $\begin{array}{r}30.5 \\
19.6 \\
14.1 \\
13.0 \\
13.7 \\
10.4 \\
8.2 \\
5.4 \\
5.4 \\
5.3 \\
5.9 \\
3.7 \\
2.3 \\
2.0 \\
2.9 \\
2.2 \\
2.8 \\
1.7 \\
1.1 \\
.9 \\
1.0 \\
.8 \\
.4 \\
.5\end{array}$ \\
\hline 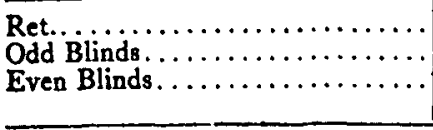 & 229 & 331 & 207 & 303 & 116 & 183 & 141 & 256 & 93 & 153 & 81 & $215 \mid$ & 64 & 161 & 56 & 139 & 44 & 135 & 10 & & & $\begin{array}{rr}= & 1,041 \\
= & 963 \\
= & 952 \\
= & 2,956\end{array}$ & $\begin{array}{l}\text { Ype 2) } \\
\text { ype 1). }\end{array}$ \\
\hline
\end{tabular}

(2)

1 In this table the order of lettering is that shown in Fig. I, used for Group I. Group 2 responded to a different lettering of parts of the maze, but the parts were identical with those here indicated. 
entrance to blinds near the goal are fully overcome under normal conditions, the final stages of correction of errors nearer the entrance (errors which persist longer) occasionally throw the subject into enough confusion to cause additional entrances to blinds later encountered. This agrees with the writer's results on twenty-four white rats, published in the monograph already cited.

Table I. shows also a general tendency for the errors near the goal to be eliminated first. The persistence of entrances to some of these blinds by a few of the subjects, who did not quickly get hold of the principle that repetition of letters already called out means that the path can be shortened, tends to obscure this general backward elimination tendency somewhat. A judgment as to the nature of this tendency from the absolute number of errors shown in this table is, however, to be made with some degree of caution; for the number of errors near the goal is smaller than that of errors near the entrance, in conformity with the expectations based on the law of chance. If learning advances at an equal rate, absolutely, in all parts of the maze, which it may or may not do, we should expect the earlier disappearance of errors near the goal. We shall consider in a subsequent paragraph the question of the relative rate of learning per unit of practice in the different parts of the maze.

Table II. gives the medians of the last trials in which the several nineteen subjects entered the different parts of the maze, and shows, therefore, in a manner different from that employed in Table I., that in general the errors nearer the goal are eliminated first. A graphical representation of these data is given in Fig. 2. Table II. and Fig. 2 also show that errors of return toward the entrance on emergence from blind alleys are eliminated earlier in the learning of the maze than are errors of going into the blinds. The unnumbered parts of the maze-the parts lettered $\mathrm{P}, \mathrm{V}, \mathrm{I}, \mathrm{K}, \mathrm{E}, \mathrm{B}, \mathrm{T}, \mathrm{C}, \mathrm{Y}$, and $S$, contain all the errors of return. On the average the return errors were eliminated 2.1 trials earlier than were the errors of blind-alley entrance. The ratio of 2.I to the median of the total number of trials to learn the maze, II, is an 
appreciable amount, showing that the early elimination of return runs is a general law supported by our mental maze experiment as well as by our experiments on rats in different forms of mazes.

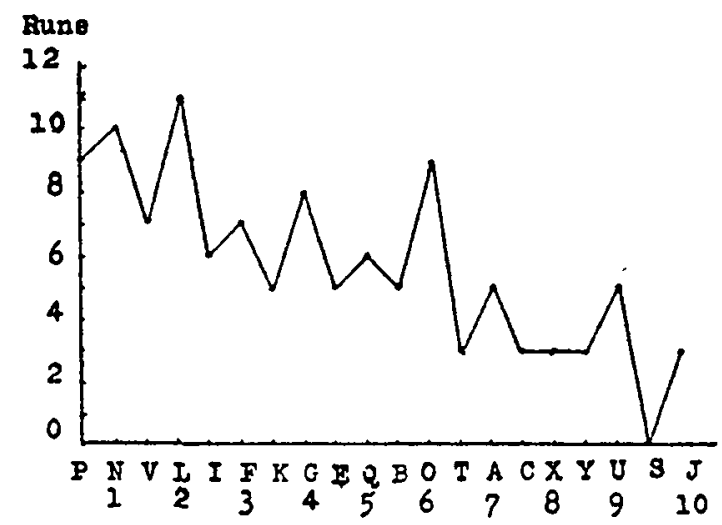

Fic. 2. The letters and numbers under the horizontal line indicate different parts of the maze, and the vertical units indicate the number of the trial on which the last error was made, each number being the median of nineteen subjects. Errors near the goal were eliminated first, and errors of return were eliminated before errors of entrance to blinds.

\section{TABLE II}

The Nusber under each Part of the Maze Indicates the Medun of the Last

Entrance to that Part by the Nineteen Subjects. Numbers Above the Letters Stand for Blind Alleys

\section{Parts of Maze}

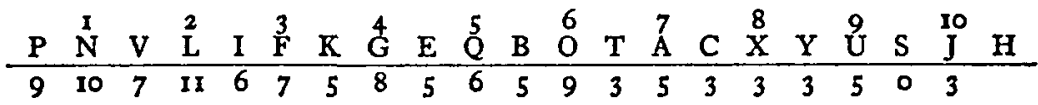

There are yet other facts pointing to the law of early elimination of return runs. On the basis of probability, strictly, there should be just half as many return errors as errors of entrance to blinds, since the chance is $I: 1$ that a return run (using the term "run" in the mental maze as we have used it in respect to the animal maze) will be made on the subject's emergence from a cul de sac; and if a special habit of keeping the forward direction does not develop, we should expect this ratio of $1: 2$ of the number of return errors to the number of blind-alley-entrance errors, to remain constant. Table III., which gives these two kinds of errors 
separately as well as combined, shows that this ratio, column (4), rapidly decreases from .83 , the highest value it has, to o. This fact, that the forward direction habit develops much

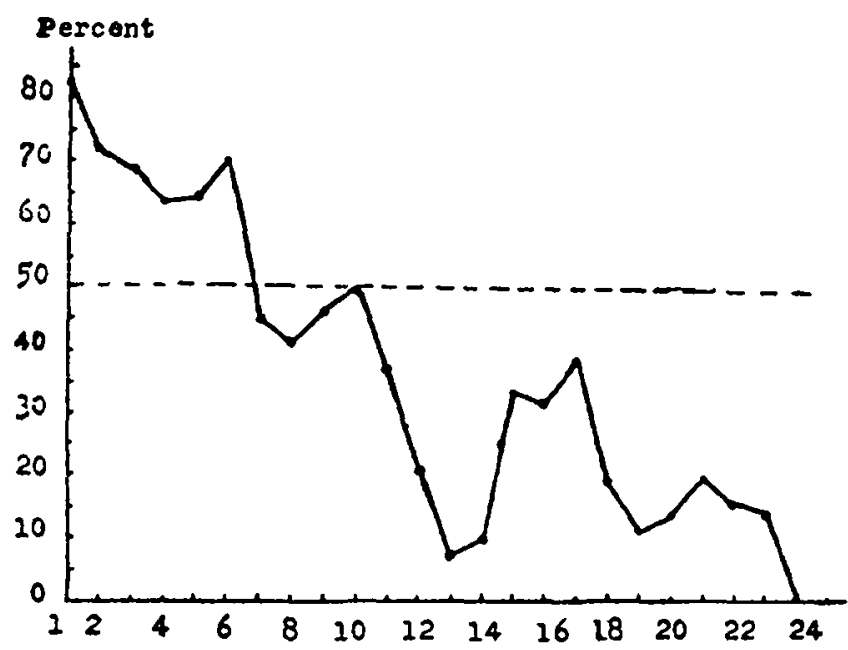

Frc. 3. Units on the base line are trial numbers, and those on the vertical line indicate the ratio of the number of return errors to that of blind-alley-entrance errors. Ratio starts above the expected .50 and rapidly decreases, showing the development of the habit of keeping the forward direction in the maze.

faster in maze learning than do the avoidance-of-blind-alley habits, seems to be of much importance in a proper understanding and analysis of maze learning, though until of late it has been wholly overlooked. This change in the ratios represented in Table III. is shown graphically in Fig. 3.

Table III. and Fig. 3 show clearly, it should also be remarked, another tendency of importance to maze learning, and probably to any kind of actual learning as distinct from mere development of skill in a mechanical performance. These data show that our human subjects had a strong tendency, persisting through the first six trials, to stay by the old and familiar rather than to venture into the novel, a tendency that in this case directly hindered learning and, as the individual records show, differentiated markedly between the good and the poor maze learners. This tendency is shown in the table and graph by the fact that the ratios mentioned 


\section{TABLE III}

Comparison of the Two Important Kinds of Errors through Successive Truls in the Mental Mnze (19 Subiects)

\begin{tabular}{|c|c|c|c|c|c|c|c|c|c|}
\hline Trial & $\begin{array}{c}\text { (1) } \\
\text { B.A. } \\
\text { Ertors }\end{array}$ & $\begin{array}{c}(a) \\
\text { Retum } \\
\text { Errors }\end{array}$ & $\begin{array}{l}\text { (3) } \\
\text { Total } \\
\text { Errors }\end{array}$ & $\left|\begin{array}{c}\text { Ratio } \\
(2) \text { to } \\
(x)\end{array}\right|$ & Trial & $\begin{array}{l}\text { B. } \\
\text { Enors }\end{array}$ & $\begin{array}{l}\text { (2) } \\
\text { Return } \\
\text { Esrors }\end{array}$ & $\begin{array}{l}\text { Th) } \\
\text { Total } \\
\text { Emors }\end{array}$ & 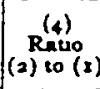 \\
\hline & 295 & 245 & 540 & .83 & 13 & $4 I$ & 3 & 44 & .07 \\
\hline & 218 & 154 & 372 & $.7 I$ & 14. & 34 & 3 & 37 & .09 \\
\hline 3. & 159 & ro8 & 267 & .68 & 15 & 40 & 13 & 53 & .33 \\
\hline & 152 & 95 & 247 & .63 & 16 & 32 & 10 & 42 & .31 \\
\hline & $\times 59$ & IOI & 260 & .64 & 17 & 39 & 15 & 54 & .38 \\
\hline & 116 & $8 I$ & 197 & .70 & $18 . \ldots$ & 28 & 5 & 33 & .18 \\
\hline & 107 & $4^{8}$ & 155 & .45 & $19 \ldots$ & 18 & 2 & 20 & . II \\
\hline & 73 & 30 & 103 & .41 & 20. .. & 15 & 2 & 17 & .13 \\
\hline 9 & 70 & 32 & 102 & .46 & $21 \ldots$ & 16 & 3 & 19 & 99 \\
\hline & 68 & 33 & IOI & .49 & 22 . & 13 & 2 & 15 & .15 \\
\hline & 82 & 30 & 112 & .37 & 23. & 7 & $I$ & 8 & .14 \\
\hline 12. & 59 & 12 & 71 & .20 & 24 & 9 & 0 & 9 &.$\infty$ \\
\hline
\end{tabular}

exceed, in the first six trials, the .50 to be expected on the law of probability. The expected ratio is very greatly exceeded in the first trial, in which the effects of the learning were least marked, reaching .83 or 166 per cent. of what is expected by chance. The individual differences with respect to this tendency are so noticeable that the writer feels the tendency will be much more marked in the case of groups of subjects of low mental caliber than in that of subjects of fair ability. Whether this difference among individuals could be made helpful in diagnostic work is a question that we must leave for the present time, one that seems to be worth following out in separate experiments by students having considerable contact with lower grades of mentality. The tendency thus to repeat unprofitable responses in the maze seems not to be very different from the perseverative tendency noted by various experimenters on low grade and on certain types of disorganized minds. Smaller differences in this regard between normal subjects should not, however, be exaggerated as to their significance. What we need just at present is more data.

It seems, then, that the first important step in learning the maze is that of keeping the forward direction, of venturing into ever new choice alternatives. Some of the more clever subjects seemed early to recognize explicitly that return was 
unprofitable, and therefore to guard against it; but often the avoidance of the return seemed to come with profitless repetition more or less unconsciously. Even when the principle of infallible assistance to keeping the forward direction was not explicitly recognized, as was ascertained by quizzing the subjects after the experiment was over, subjects often behaved as if they had the principle in mind. The principle is that of choosing in any subsequent choice the one of the letters that occurred as one of the alternatives-the rejected onein the previous presentation. For example, if the experimenter calls out $\mathrm{N}$ and $\mathrm{V}$ and the subject chooses $\mathrm{N}$, then $\mathrm{V}$ must be one of the next alternative choices; if then $V$ is chosen, $L$ and $I$ are presented. If $I$ is chosen $L$ is not repeated, but if $L$ is chosen I must be repeated with $V$ for the next choice. The rationale of this is not, of course, evident even to the best subjects, for they do not see the maze; but they often notice the simple fact of such repetition of one of the letters after certain choices which they soon learn to be erroneous, and the absence of it with other, or correct, choices, and consciously and rationally govern themselves accordingly. But, and this is the interesting thing after all, subjects who do not have such explicit recognition of the principle, nevertheless show in their behavior that they are governed by it, as they must be to take this first step in mental maze learning. They, at least, show no recognition of the principle in their unsolicited remarks during the experiment, or in answers to questions seeking evidence of such recognition, after the learning process has been completed. As Swift and other experimenters have found regarding the unconscious adoption of better methods and movements in ball-tossing, so we find here, that our subjects were often forced by the general fruitlessness of their reactions to adopt other modes of response resembling principles or rules of action, without any explicit recognition of the principles. The explicit recognition of a principle often comes after the student has unconsciously followed it for some time. Not infrequently the principle considered here is adhered to only in part, and reactions that fail to follow it throw the subject out of keeping 
the forward direction. Thus a subject given the choice between $\mathrm{T}$ and $\mathrm{O}$ may choose $\mathrm{O}$, and when the next pair of alternatives, $T$ and $B$, is presented he may by some accident choose $B$, after which, following the rule closely, he is taken back entirely to the starting place in the maze. This error occurred occasionally whether or not the subject explicitly recognized the principle of choosing the letter repeated. It may even be doubtful, as a study of rational learning by the writer seems to indicate it is, whether explicit recognition of a necessary principle in any case of learning is really a sine qua non of the learning. This question we cannot follow out further in the present paper.

Another point of interest may be considered here. From our statement on the second page, of the relative number of times that each blind alley would be passed in each trial by a subject following strictly the law of probability, we can figure how many errors may be expected at each part of the maze by our total of nineteen subjects, and can then compare this expected number with the actually obtained number. On the basis of chance there should be two thirds as many errors of entrance into the several blinds as there are runs made past them; for the chance of entrance to any blind is $1: 1$, and the chance of passing the blind, whether or not it is entered in $3: \mathbf{I}$. But here we are at once confronted by two difficulties. First, as a result of the learning that each subject shows increasingly toward the end of his practice, the number of runs past the blind alleys will, of course, greatly increase proportionately over the number of errors of entrance into them. But if learning goes on in equal proportion to the amount of exercise in all parts of the maze, we may obviously disregard this fact that the errors at each bifurcation gradually approach zero as the learning approaches perfection. If learning goes on more rapidly, proportionately, at one part of the maze than at another, this fact ought to reveal itself by relatively fewer errors all told at this point. Entrance into the blinds would discontinue earlier, comparatively, or would at any rate occur less frequently in proportion to exercise at the place in question, than at other places in the maze. We thus avoid the first possible difficulty. 
The second difficulty that we meet in figuring the expected number of errors at the several parts of the maze is a statistical one. It will be recalled that we found the relative number of runs past each blind alley in the forward direction in $n$ trials to be as follows from the first to the tenth blind, respectively: $13.33 n$, 10.00n, 7.50n, $5.62 n, 4.22 n, 3.16 n, 2.37 n$, $1.78 n, 1.33 n$, and $n$. The determination of these numbers was based, however, on the assumption of complete return runs. In our present experiment, as in most experiments on animal learning in the maze as well, return runs are seldom complete. An animal returning from the tenth blind, for example, is very apt to enter a blind on its return run and to get started again in the forward direction as it emerges from this blind. Our coefficients of $n$ are therefore too great for the blinds near the entrance or beginning place in the maze, and it is no simple matter to correct these coefficients from the effect of the assumption of complete return runs; for an animal in the maze may be sent back and forth many times and in diverse ways, according to the expectations of probability, before reaching the food box. The difficulty is not an insuperable one, however.

On the basis of chance one half of the runs reaching any blind will become entrances into it. The entrances to the tenth blind will, therefore, equal one half of $1.33 n$, the runs past the ninth blind, or $.67 n$. Or otherwise derived, the number of entrances to any given blind is equal to two thirds the number of runs past it, the forward direction runs only being considered, since, as has been shown, the runs past equal three fourths the runs to it $(1 / 2+1 / 4)$, and the number of runs into it equals one half the runs to it $(1 / 2: 3 / 4=2: 3)$. Thus $2 / 3$ of $n$, is $.67 n$, the number of entrances to the tenth blind. It is to be remembered that on the basis of the criteria of errors adopted in the present study-any entrance to a blind on a forward run or a return toward the entrance of the maze on emergence from any blind entered on a run in either direction, being an error-there can be no errors of entrance to blinds on return runs. On the basis of these facts we have worked out Table IV. 


\section{TABLE IV}

This Table Shows the Return Runs Past Each Blind Alley yrom Those Nearer the Goal-end or the Maze, on the a8sumption of Complete Return Runs from Each Blind. It also Shows the Number of Errors Expected at Each Buind on tae Law of Chance, Corrected from the Effects of Thib Assumption. See Text for Explanation

\begin{tabular}{|c|c|c|c|c|c|c|c|c|c|c|c|}
\hline & \multicolumn{11}{|c|}{ The Blind Alleys of the Maze } \\
\hline & $x$ & I & 3 & 4 & 5 & 6 & 7 & 8 & 9 & xo & \\
\hline $\left.\begin{array}{l}(1) \\
(2) \\
3\end{array}\right)$ & $\begin{array}{r}13.33 n \\
8.89 n \\
4.44 n \\
\end{array}$ & $\begin{array}{r}10.00 n \\
6.67 n \\
3.33 n \\
\end{array}$ & $\begin{array}{l}7.50 n \\
5.00 n \\
2.50 n\end{array}$ & $\begin{array}{l}5.62 n \\
3.75 n \\
1.86 n\end{array}$ & $\begin{array}{l}4.22 n \\
2.81 n \\
1.41 n \\
\end{array}$ & $\begin{array}{l}3.16 n \\
2.11 n \\
1.05 n\end{array}$ & $\begin{array}{r}2.37 n \\
1.58 n \\
.79 n \\
\end{array}$ & $\begin{array}{r}1.78 n \\
1.19 n \\
.59 n \\
\end{array}$ & $\begin{array}{r}1.33 n \\
.89 n \\
.44^{n} \\
\end{array}$ & $\begin{array}{r}n \\
.67 n \\
.33 n \\
\end{array}$ & \\
\hline $\begin{array}{l}(4) \\
\text { ( } 5) \\
(6) \\
(7) \\
(8) \\
(9) \\
(10) \\
(11) \\
(12)\end{array}$ & $\begin{array}{l}.025 n \\
.04 n \\
.08 n \\
.14 n \\
.25 n \\
.44 n \\
.79 n \\
1.41 n \\
2.50 n\end{array}$ & $\begin{array}{l}.03 n \\
.06 n \\
.11 n \\
.19 n \\
.33 n \\
.59 n \\
1.05 n \\
1.86 n\end{array}$ & $\begin{array}{r}.04 n \\
.08 n \\
.14 n \\
.25 n \\
.44 n \\
.79 n \\
1.41 n\end{array}$ & $\begin{array}{l}.06 n \\
.11 n \\
.19 n \\
.33 n \\
.59 n \\
1.05 n\end{array}$ & $\begin{array}{l}.08 n \\
.14 \pi \\
.25 n \\
.44 n \\
.79 n\end{array}$ & $\begin{array}{l}.11 n \\
.19 n \\
.33 n \\
.59 n\end{array}$ & $\begin{array}{l}.14 n \\
.25 n \\
.44 n\end{array}$ & $\begin{array}{l}.19 n \\
.33 n\end{array}$ & $.25 n$ & $\begin{array}{c}\text { Returns fr } \\
\text { " } \\
\text { " } \\
\text { " } \\
\text { " } \\
\text { " }\end{array}$ & $\begin{array}{cc}\text { rom } & \text { 10th } \\
\text { " } & 9 \text { th } \\
\text { “ } & 8 \text { th } \\
\text { “ } & 7 \text { th } \\
\text { “ } & 6 \text { th } \\
\text { “ } & 5 \text { th } \\
\text { “ } & 4 \text { th } \\
\text { “ } & 3 \mathrm{~d} \\
\text { " } & \text { 2d }\end{array}$ \\
\hline $\begin{array}{l}(13) \\
14,3)\end{array}$ & $\begin{array}{l}5.68 n \\
4.44 n \\
\end{array}$ & $\begin{array}{l}4.22 n \\
3.33 n\end{array}$ & $\begin{array}{l}3.15 n \\
2.50 n \\
\end{array}$ & $\begin{array}{l}2.33 n \\
1.86 n \\
\end{array}$ & $\begin{array}{l}1.70 n \\
1.41 n\end{array}$ & $\begin{array}{l}1.22 n \\
1.05 n\end{array}$ & $\begin{array}{l}.83 n \\
.79 n\end{array}$ & $\begin{array}{l}.52 n \\
.59 n\end{array}$ & $\begin{array}{l}.25 n \\
.44 n\end{array}$ & $.33 n^{\text {Tot }}$ & tals \\
\hline $\begin{array}{l}(17) \\
(18) \\
(19) \\
\end{array}$ & $\begin{array}{r}11.12 n \\
8.34 n \\
5.56 n \\
\end{array}$ & $\begin{array}{l}8.55 n \\
6.42 n \\
4.28 n \\
\end{array}$ & $\begin{array}{l}6.66 n \\
5.00 n \\
3.33 n \\
\end{array}$ & $\begin{array}{l}5.19 n \\
3.90 n \\
2.60 n \\
\end{array}$ & $\begin{array}{l}4.11 n \\
3.08 n \\
2.05 n \\
\end{array}$ & $\begin{array}{l}3.27 n \\
2.45 n \\
1.63 n \\
\end{array}$ & $\begin{array}{l}2.62 n \\
1.97 n \\
1.31 n \\
\end{array}$ & $\begin{array}{l}2.11 n \\
1.58 n \\
1.05 n\end{array}$ & $\begin{array}{r}1.69 n \\
1.27 n \\
.85 n \\
\end{array}$ & $\begin{array}{l}1.33 n \\
1.00 n \\
.67 n=\end{array}$ & $23.33 n$ \\
\hline
\end{tabular}


The first row of the table shows the relative number of runs past each blind in the forward direction, on the assumption of complete returns. The next row gives the expected entrances to the several blinds in these forward runs. The third row shows the number of return runs expected from each blind on emergence of the subject from the blind. It is clear that one half of the choices on emergence from the blinds will be in the wrong direction. We must figure, then, the relative number of returns from the tenth blind that will pass the ninth, the eighth, the seventh, the sixth, the fifth, the fourth, the third, the second, and the first blind, respectively. Obviously, of the $.33 n$ returns from the tenth blind, three fourths of this number, or $.25 n$, will get past the ninth blind; three fourths of these, or $(3 / 4)^{2}$ of $.33 n$, will get past the eighth blind, that is, .I9n runs; $(3 / 4)^{3}$ of $.33 n$, or .1 $4 n$ will pass the seventh; and so on, as shown in the table. Only $.025 n$ of the $.33 n$ returns from the tenth blind will pass the first blind. The same procedure is followed for the return runs from the ninth, the eighth, the seventh, the sixth, the fifth, the fourth, the third, and the second blind. The results of these calculations are clearly indicated in the table. Then summarizing all these returns past each blind in their respective columns, we get row (13), which when added to row (14,3), the returns from the several blinds, gives us for each blind the total returns past or from it toward the entrance, corrected from the effects of the assumption of complete returns, row (15). Now since each trial must end with one more forward than backward run past each blind, it is clear that to these totals we must add $n$, to get the corrected number of forward runs past each blind according to chance only. This gives us row (17) in the table. But in this result we get $1.33 n$ runs past the tenth blind alley on our assumption of $n$ trials, which is impossible. We must therefore reduce the values of row ( 17 ) by the ratio $n: 1.33 n$, or $3: 4$, by which process we get row (18). Thus having the realtive number of runs in the forward direction past each blind in the maze, we can easily find the expected number of errors of entrance into each blind according to our present criteria and conditions of experimentation. 
Since the ratio of errors at each blind to runs past the blind is $2 / 3$, as we have already seen, we need only take $2 / 3$ of the values given in row (18). In row (19), then, we have the expected number of errors of entrance into each blind from the first to the tenth, corrected from the errors of any assumptions not in agreement with the conditions of the present experiment.

We can now proceed to compare our obtained distribution of errors of entrance into blind alleys with the distribution expected on the basis of chance. The sum of all the expected errors as given in the eighteenth row of Table IV. is $23.33 n$. Dividing 23.33 into 1915 , the total number of blind-alleyentrance errors made by our nineteen subjects, we get 82.08 , the value of $n$ for the present calculation, as is evident from the equation,

\subsection{3n (expected errors) $=1915$ (obtained errors).}

We can then determine how our obtained errors should be distributed by chance purely, by multiplying each of the coefficients of $n$ in row (19) of Table IV. by 82.08. Table V. gives the results thus obtained, the expected errors at each blind, and it also gives the number of errors actually found at each blind by our total of nineteen subjects. The ratios

\section{TABLE V}

Distribution of Errors Expected on the Basis of Chance, and of Errors Actually Made ay Nineteen Subjects in the Ten Blind Alleys of THE MAzE

\begin{tabular}{|c|c|c|c|c|c|c|c|c|c|c|c|}
\hline \multirow{2}{*}{ Blind Alleys } & \multicolumn{10}{|c|}{ Errors in the Respective Blind Alleys } & \multirow{2}{*}{ Total } \\
\hline & I & $=$ & 3 & 4 & 5 & 6 & 7 & 8 & 9 & ro & \\
\hline $\begin{array}{l}\text { Errors expected........... } \\
\text { Errors obtained.......... } \\
\text { Ratio, exp. to obt........ }\end{array}$ & $\left|\begin{array}{l}456 \\
331 \\
I \cdot 38\end{array}\right|$ & $\begin{array}{l}35 \mathrm{I} \\
303 \\
1.13\end{array}$ & $\begin{array}{l}273 \\
183 \\
1.49\end{array}$ & $\begin{array}{l}213 \\
256 \\
.83\end{array}$ & $\begin{array}{l}168 \\
153 \\
1.10\end{array}$ & $\begin{array}{l}134 \\
215 \\
.62\end{array}$ & $\begin{array}{l}108 \\
161 \\
.67\end{array}$ & $\begin{array}{r}86 \\
139 \\
.62 \\
\end{array}$ & $\begin{array}{r}70 \\
135 \\
.52 \\
\end{array}$ & $\mid \begin{array}{c}55 \\
39 \\
1.41\end{array}$ & $\begin{array}{l}1,914 \\
1,915\end{array}$ \\
\hline
\end{tabular}

of the expected to the actually obtained errors are also given. The larger the ratio is at any part of the maze, the greater has been the learning rate, proportionately, at that place. It will be seen by an examination of the table that the expected errors exceed the actually obtained errors noticeably at the 
first three, and the fifth, blinds, and also at the last blind. This we interpret to mean that the subjects had to develop rather specifically the principle of avoidance of blinds-and that roughly the first and the last members of the series of associations to be made were the easiest formed. This is in agreement with results usually obtained in the formation of relatively short series of associations. On the whole, then, transfer effects from one part of the maze to another seem to be slight, despite the fact that a simple rule when once learned in any part of the maze will almost infallibly, if not entirely so, guide the subject through other parts of the maze without return runs. It is true that the rule will not prevent entrances into blinds, but it will prevent return runs, which often increase greatly such entrances. The experimenter believes that the amount of transfer in this sense, and measured as here suggested, will correlate fairly highly with the intelligence of the subject. This, however, is a matter that we can not discuss in the present paper.

It is important to note that this fact of different relative rates of learning at different parts of the maze, has no relation to the backward elimination tendency in maze learning, also found to hold with our subjects in the mental maze, for we are now considering learning in relation to the proportion of actual practice in different parts of the maze; whereas the backward elimination tendency was found to depend on the greater learning coefficients (presently to be defined) of the blinds near the goal-end of the maze. The very low ratio of .52 at the ninth blind is probably due to the many errors of one subject at this point, errors persisting down to the second from the last trial for this subject, that is, far beyond the point of complete learning by all the other subjetcs. Our data, especially those for later trials reached only by a few subjects, need verification on many more subjects, a matter that is not so difficult now that the statistical calculations have been made. The writer, however, believes that the tendency here shown, for the learning to be more rapid at the two ends of the maze, irrespective of the backward elimination tendency, will hold. 
With the data shown in Table IV., giving the relative number of errors actually to be expected at the different blind alleys on the law of probability, we are able finally to take still another step of importance to the theory of maze learning: we can improve upon the results shown on our second page, and can find mathematically the relative advantage at each blind of exercise in going past over exercise in going into the blind. The results of such determinations are given in general terms in the left half of Table VI. The next two columns of the table give the ratios when $n=I$

\section{TABLE VI}

Learning Coepficients at the Sefveral Blind Alleys of tge Maze, also Comparisons of Advantage for learning at the Tenta Over that at the

First Blind AlLey

\begin{tabular}{|c|c|c|c|c|c|}
\hline \multirow{3}{*}{$\begin{array}{l}\text { Bliad } \\
\text { Alleys }\end{array}$} & \multicolumn{3}{|c|}{ Leerning Coefficients } & \multirow{3}{*}{ Value of $x$} & \multirow{3}{*}{$\begin{array}{l}\text { Advantuge for Learaing } \\
\text { at the 1oth Over that of } \\
\text { 1st Blad Alley for } \\
\text { Different Values of }\end{array}$} \\
\hline & \multirow{2}{*}{ In General Terms } & \multicolumn{2}{|c|}{ When } & & \\
\hline & & $x=x$ & $x=2$ & & \\
\hline Ist. & $8.34^{n}: 8.34^{n}-.25$ & $1.03 \mathrm{I}$ & 1.015 & I & $1.29^{1}$ \\
\hline & $6.42 n: 6.42 n-.25$ & $1.04 \mathrm{I}$ & 1.019 & 2 & 1.13 \\
\hline & $5.00 n: 5.00 n-.25$ & 1.053 & 1.026 & 3 & 1.08 \\
\hline 4 & $3.90 n: 3.90 n-.25$ & 1.068 & 1.033 & 4 & 1.06 \\
\hline & $3.08 n: 3.08 n-.25$ & 1.088 & 1.042 & 5 & 1.05 \\
\hline 6 & $2.45^{n}: 2.45 n-.25$ & 1.114 & 1.054 & 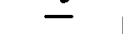 & \\
\hline 7th. & $1.97 n: 1.97 n-.25$ & 1.145 & 1.068 & 10 & 1.02 \\
\hline 8 th. & $1.58 n: 1.58 n-.25$ & 1.188 & 1.086 & - & \\
\hline 9th. & $1.27 n: 1.27 n-.25$ & 1.245 & 1.109 & 20 & $1.0 \mathbf{r}$ \\
\hline Ioth. & $1.00 n: 1.00 n-.25$ & 1.333 & 1.143 & $\infty$ & 1.00 \\
\hline
\end{tabular}

and 2, respectively. These ratios we have called the learning coefficients at the several blind alleys. The learning coefficient at any blind is the ratio of the expected number of runs past that blind in the forward direction to the expected number of runs into it (from either direction). It will be noted that the learning coefficients for the two values of $n$ given in the table gradually increase from a small value at the first blind to an appreciably greater value at the tenth blind. A coefficient of 1.00 indicates no learning possibility, so far as frequency effects-the only ones considered here-are concerned; for

1. This advantage is found by dividing the learning coefficient at the roth blind alley by that at the 1 st; e.g., $1.333 \div 1.031=1.29$. 
in the case of a blind with such a coefficient, the exercise in running into the blind exactly equals that of passing it.

It will be seen that the learning coefficients. not only constantly decrease from the tenth back to the first blind, but that this advantage for the blinds near the goal constantly decreases with increasing values of $n$. To make this plain we have calculated the advantages at the tenth over that at the first blind alley, when $n$ is $1,2,3,4,5,10,20$, and infinity, respectively. This advantage is found by dividing the learning coefficient of the tenth blind by that of the first, for any value of $n$. Our results, given in the last column of the table, show a constantly decreasing advantage for the tenth blind over the first as the values of $n$-that is, the number of trials by any subject-increase. When $n$ becomes very great the learning advantage of the near-goal blinds becomes negligible. This is due to the fact that the learning coefficients at all the blinds approach unity as their limit. This general law of decreasing learning advantage of the tenth over the first blind with increasing values of $n$ is important. It suggests one reason why learning in mazes goes on more rapidly in the early trials (when $n$ is small) than in later ones. Another reason has already been pointed out by the writer in the monograph cited above, namely, that the return runs on emergence from blinds disappear relatively early in the learning of the maze, and with them all the probabilities of error due to re-passing blinds nearer the entrance of the maze.

The table in question also makes plain two minor points of interest in maze learning: first, that the learning coefficients reach practically a zero value, a ratio of unity, earlier in the learning process for the near-entrance blinds than for the near-goal blinds, this being really a corollary of what has already been said; second, that the learning advantage for the near-goal blinds over the near-entrance blinds rapidly increases for low values of $n$-or in the early trials of any subject-with increase in the number of blinds in the maze. From this latter fact we should expect that backward elimination of errors in the maze would be much more marked in mazes with many blinds than in mazes with but few blinds. 
We have yet no data from mental mazes of different degrees of difficulty to verify this deduction. It is obvious, moreover, that mazes do not increase in difficulty directly with increase in the number of blinds.

\section{SUMMary}

We have developed an empirical method of studying analytically one of the kinds of learning used in many laboratories, namely maze-learning. Our method applies only to human subjects, but it enables us to study maze-learning independently of the various spatial factors peculiar to individual mazes, and thereby better to determine the general laws involved. Our results from nineteen subjects show convincingly, not only that backward elimination of blind-alley entrances is the rule in maze learning, but also that return runs on emergence from blinds are eliminated earlier in the process than are blind alley entrances. Subjects learn both consciously and unconsciously to follow a simple rule the value of which develops in their random efforts, a rule that leads them to depart from the unprofitable repetitions and to venture into new parts of the maze. There is no qualitative difference between the reactions of subjects who recognize this rule explicitly and those of subjects in whose minds the rule does not come out consciously. In this tendency to depart from the repetition of profitless choices, to go against the valueless effects of frequency, subjects differ materially, the better learners showing greater initiative than the poorer ones.

The experimental results are at every hand compared with expectations based on the law of probability, and mathematical determinations of the learning coefficients at each of the blind alleys are made. The advantages for learning at the tenth blind over those at the first blind are found, and it is shown that this advantage rapidly decreases with successive trials by each subject. This probably is one reason for more rapid learning in the early trials, another being the fact that return runs are eliminated relatively early as compared with errors of entrance to the several blinds.

A method is worked out also of comparing the distribution 
of errors in the maze with the expected distribution based on chance, and it is found, in agreement with other experiments on association, that the first and the last members of the series (parts of the maze here) are mastered more readily than are the members between the extremes. Finally it is found that the effects of learning in one part of the maze are not noticeably transferred to other parts. A number of problems for further investigation are suggested. 